\title{
Induction of c-Jun immunoreactivity in spinal cord and brainstem neurons in a transgenic mouse model for amyotrophic lateral sclerosis
}

\author{
Dick Jaarsma $^{\mathrm{a}, *}$, Jan C. Holstege ${ }^{\mathrm{a}}$, Dirk Troost ${ }^{\mathrm{c}}$, Maria Davis ${ }^{\mathrm{a}}$, Josette Kennis ${ }^{\mathrm{a}}$, Elize D. Haasdijk ${ }^{\mathrm{a}}$, \\ Vianney J.M.B. de Jong ${ }^{b}$ \\ ${ }^{a}$ Department of Anatomy, Erasmus University, Rotterdam, The Netherlands \\ ${ }^{\mathrm{b}}$ Department of Experimental Neurology, Academic Medical Centre, Amsterdam, The Netherlands \\ ${ }^{\mathrm{c}}$ Department of Pathology, Academic Medical Centre, Amsterdam. The Netherlands
}

Received 26 August 1996; revised version received 17 October 1996; accepted 21 October 1996

\begin{abstract}
Transgenic mice carrying amyotrophic lateral sclerosis (ALS)-linked superoxide dismutase 1 (SOD1) mutations develop a motoneuron disease resembling human ALS. c-Jun is a transcription factor frequently induced in injured neurons. In this study we have examined the distribution of c-Jun-immunoreactivity in the brainstem and spinal cord of transgenic SODl mice with a glycine 93 alanine (G93A) mutation. In non-transgenic littermates c-Jun immunostaining was predominantly situated in motoneurons. The number of c-Jun immunoreactive motoneuron was reduced in SOD1(G93A) mice due to pronounced loss of motoneurons. In SOD1(G93A) mice, however, c-Jun-immunoreactivity was strongly induced in neurons in the intermediate zone (Rexed's laminae V-VIII and X) of the spinal cord and throughout the brainstem reticular formation. These findings are of interest since increased levels of c-jun also have been found in the intermediate zone of the spinal cord of ALS patients. Thus c-Jun may be involved in the neurodegenerative processes both in ALS and in motoneuron disease in SOD1(G93A) mice.
\end{abstract}

Keywords: Immediate early genes; Spinal interneurons; Motoneuron disease; Reticular formation

In approximately $20 \%$ of the patients with the familial form of amyotrophic lateral sclerosis (FALS) (i.e. 2\% of all amyotrophic lateral sclerosis (ALS) cases) the disease has been linked to missense mutations in the cytosolic copper/zinc superoxide dismutase (SOD1) gene [14]. Transgenic mice carrying FALS-linked mutated human SOD1 (hSOD1), but not those with wild-type hSOD1, develop a progressive motoneuron disease resembling human ALS $[5,13,16]$. Since the symptoms and pathological features of sporadic ALS and FALS are virtually indistinguishable it has been assumed that sporadic ALS and FALS may share common mechanisms of pathogenesis downstream of a primary defect. This would mean that identification of pathogenic mechanisms in transgenic

\footnotetext{
* Corresponding author. Department of Anatomy EE12.53, Erasmus University, P.O. Box 1738, 3000 DR Rotterdam, The Netherlands. Tel.: +31 104087309 ; fax: +31 104365780 ; e-mail:

jaarsma@anat.fgg.eur.nl
}

SOD1 mice is relevant not only for SOD1-linked ALS, but also for sporadic ALS which is responsible for more than $90 \%$ of the patients.

The transcription factor c-Jun has been implicated in the control of neuronal death and regeneration $[4,7,12]$. The expression of C-Jun can be induced in neurons by various types of injury $[3,7,12]$. Recently, it has been reported that the spinal cords of patients with sporadic ALS display a 34-fold increase of expression of c-jun mRNA [15], suggesting that c-Jun is involved in the neurodegenerative processes of ALS. In this immunocytochemical study we have investigated whether changes in c-Jun expression occur in the brains of transgenic mice expressing ALSlinked mutated hSOD1.

Transgenic mice derived from the Gurney G1-line carrying hSOD1 with a glycine ${ }^{93}$-to-alanine (G93A) mutation [5] were obtained from The Jackson Lab. (Bar Harbor, ME, USA; strain designation B6SJL-TgN(SOD1G93A)Gur). In our animal facility, mice were backcrossed 
to either a C57B16 or a FVB background, by mating hemizygote transgenic males with inbred C57Bl6 (Harlan, Zeist, The Netherlands) or outbred FVB females (Harlan, Zeist, The Netherlands). Transgenic progeny was identified by polymerase chain reaction (PCR) of tail DNA with primers specific for hSOD1 [14], and by immunocytochemistry with a monoclonal antibody against hSODl (Sigma, St. Louis, USA). At antibody dilutions up to 1:50000 intense homogeneous immunostaining was observed throughout the brain and spinal cord of transgenic mice. No hSOD1 immunostaining was visible in the brains of non-transgenic littermates.

The transgenic mice derived from The Jackson Lab., as well as transgenic C57Bl6 and FVB backcrosses began to develop clinical symptoms at 24-32 weeks of age. They had difficulty in extending their hind limbs when lifted by their tails, and frequently showed a mild tremor in one or more limbs. Subsequently, affected mice showed progressive weakness of the limbs, and 2-4 weeks later they were visibly smaller and showed disturbed locomotion, with the hindlimbs often in hyperflexed or hyperextended position. In accordance with previous observations $[2,16]$, transgenic mice developed vacuolar degeneration in axons and dendrites. Vacuoles were already present at 20 weeks of age before the onset of symptoms and were concentrated in motoneuronal cell groups. By the onset of clinical symptoms loss of motoneurons, assessed by choline-acetyltransferase (ChAT) immunocytochemistry, became apparent [10].

Both symptomatic and presymptomatic SOD1(G93A) mice and non-transgenic littermates were used in this study (Table 1). The mice were deeply anesthetized with sodium pentobarbital (60 mg/kg i.p.), and subsequently perfused transcardially with phosphate-buffered saline, followed by $4 \%$ freshly dissolved paraformaldehyde in $0.12 \mathrm{M}$ phosphate buffer ( $\mathrm{PB} ; \mathrm{pH} 7.4$ ). The brains were post-fixed overnight in the same fixative, and cryoprotected in $30 \%$ sucrose in PB for another night. Frozen 40 $\mathrm{mm}$-thick sections were cut, incubated free-floating for 48 $\mathrm{h}$ at $4^{\circ} \mathrm{C}$ with antibody against c-Jun (Ab1, Oncogene sciences) diluted 1:10000 in Tris-buffered saline, and stained employing the avidin-biotin-peroxidase complex method (ABC; Vector Lab.) with diaminobenzidine $(0.05 \%)$ as the chromogen. Adjacent sections were incubated with a monoclonal antibody against ChAT (kindly provided by Dr. Cozzari [1]) to label motoneurons. The brains of transgenic mice were always processed together with a control brain, using the same antibody and diaminobenzidine solutions.

c-Jun immunostaining was confined to nuclei of neurons. Non-transgenic littermates showed immunolabeled neurons in the hippocampus, the piriform cortex, the brainstem and the spinal cord. In the spinal cord, c-Jun immunoreactivity was confined to motoneurons, and in the preganglionic sympathetic and parasympathetic neurons. $50-77 \%$ of the motoneurons were c-Jun-positive, the majority of which displayed weak-to-moderate c-Jun immunoreactivity, whereas a few were strongly labeled (Fig. 1A and Fig. 2). In the brainstem immunoreactivity was predominantly situated in motoneurons of the cranial nerve nuclei. Other areas with c-Jun immunoreactive neurons included the rostral portion of the nucleus of the solitary tract, the raphe magnus and the mesencephalic nucleus of the trigeminal nerve (Fig. 2A).

SOD1(G93A) mice with clinical symptoms displayed a strikingly different pattern of c-Jun immunolabeling in the spinal cord and brainstem (Figs 1 and 2). In the spinal cord a large number of neurons with moderately or intensely cJun-immunostained nuclei were present throughout the grey matter. Most neurons with c-Jun-positive nuclei were situated in the intermediate zone (Rexed's laminae V-VIII and X), and were small-to-intermediate in size (8$20 \mathrm{~mm}$ in diameter). The number of c-Jun-positive neurons in the intermediate zone and dorsal horn varied between mice (Table 1). It roughly correlated with the progression of disease, i.e. animals killed at the onset of clinical disease showed fewer jun-positive neurons in the intermediate zone and dorsal horn than animals with severe muscle weakness (Fig. 2B). A few neurons with weakly c-Jun positive nuclei were observed in the intermediate zone

Table 1

Number of c-Jun-immunoreactive neurons in the intermediate zone (IZ) and dorsal horn (DH), and c-Jun-immunoreactive motoneurons in transverse sections of the L4 segment of the spinal cord of control and SOD1(G93A) mice, killed before or after onset of symptoms

\begin{tabular}{llllll}
\hline Mouse groups $(n)$ & $\begin{array}{l}\text { Age } \\
\text { (weeks) }\end{array}$ & $\begin{array}{l}\text { c-Jun-positive } \\
\text { neurons in IZ } \\
\text { and DH }\end{array}$ & $\begin{array}{l}\text { c-Jun-positive } \\
\text { motoneurons }\end{array}$ & $\begin{array}{l}\text { ChAT-positive } \\
\text { motoneurons }\end{array}$ & $\begin{array}{l}\text { c-Jun-positive } \\
\text { motoneurons/ } \\
\text { ChAT-positive } \\
\text { motoneurons }(\%)\end{array}$ \\
\hline $\begin{array}{l}\text { Non-transgenic littermates (5) } \\
\text { Pre-symptomatic OD1(G93A) }\end{array}$ & $24-32$ & 0 & $32 \pm 2(27-36)$ & $53 \pm 3(47-60)$ & $62 \pm 6(50-77)$ \\
$\begin{array}{l}\text { mice 3) } \\
\begin{array}{l}\text { Symptomatic SOD1(G93A) } \\
\text { mice (7) }\end{array}\end{array}$ & $25-34$ & $82 \pm 12(38-144)^{*}$ & $14 \pm 1(9-19)^{*}$ & $25 \pm 2(19-35)^{*}$ & $53 \pm 4(44-68)$ \\
\hline
\end{tabular}

Adjacent sections were processed for ChAT-immunocytochemistry to determine the total number of motoneurons/section. Values represent means \pm SE (range). Values are based on countings of four adjacent series of L 4 sections/animal immunostained for $c-J u n$ and $C h A T$, respectively. $* P<10^{-5}$ compared to non-transgenic littermates, unpaired $t$-test. 


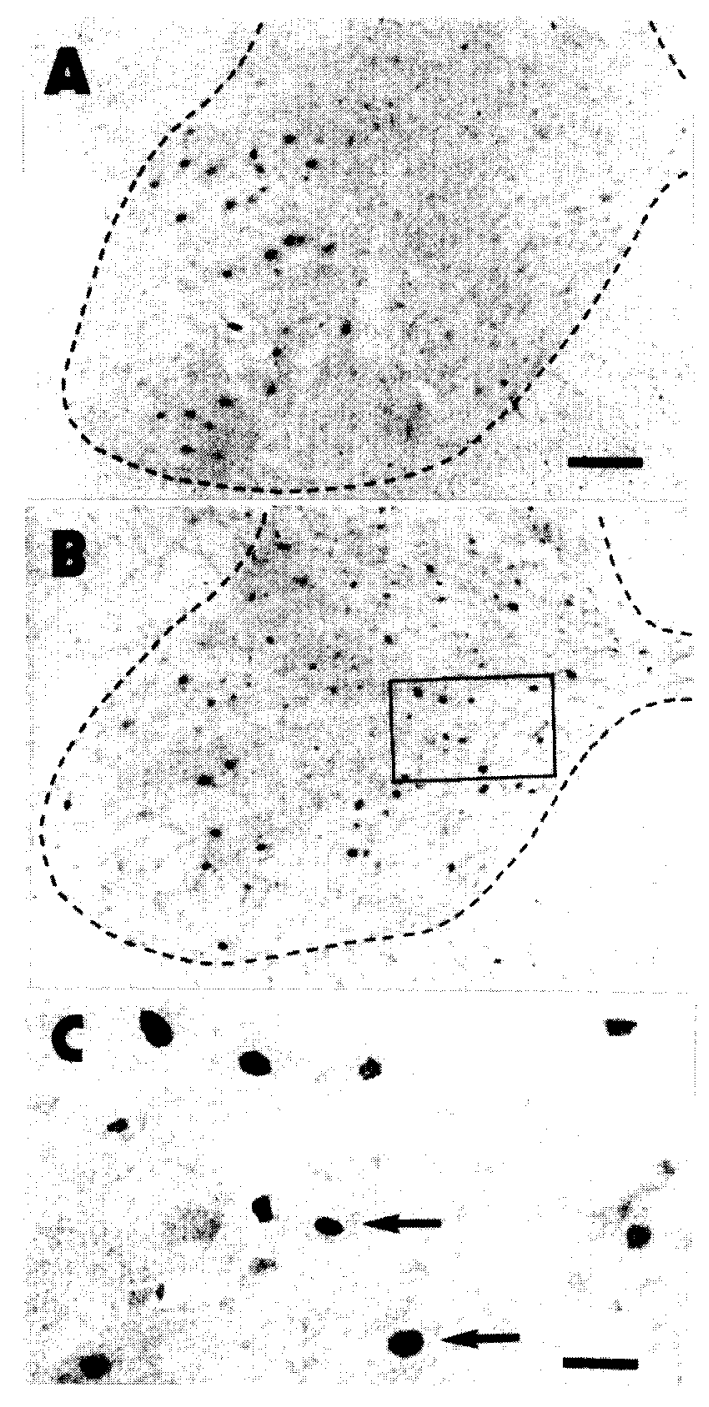

Fig. 1. Distribution of c-Jun immunoreactivity in the ventral horn and intermediate zone of the L4 spinal cord of a non-transgenic littermate (A) and a SOD1(G93A) transgenic mouse (B). (C) High magnification of insert in (B). Note strongly c-Jun-positive neuronal nuclei in the intermediate zone of SOD1(G93A) L4 spinal cord (arrows in (C)). Dashed lines in $(A)$ and $(B)$ indicate the border between the grey and the white matter. Scale bars, (A,B) $100 \mu \mathrm{m}$; (C) $25 \mu \mathrm{m}$.

of the lumbar spinal cord of one of the presymptomatic SOD1(G93A) mice. C-Jun-positive neurons other than motoneurons, preganglionic sympathetic and parasympathetic neurons, however, were never seen in the other presymptomatic SOD1(G93A) mice nor in control mice.

Spinal motoneurons of the symptomatic SOD1(G93A) mice generally displayed higher levels of c-Jun immunoreactivity than those of control mice (Fig. 1A,B). The number of spinal motoneurons expressing c-Jun immunoreactivity, however, was reduced in symptomatic SOD1(G93A) mice (Table 1). This reduction in the number of c-Jun-positive motoneurons was proportional to the amount of motoneuron loss (Table 1).

In the brainstem of symptomatic SOD1(G93A) mice, cJun-positive neurons were present throughout the medul- lary, pontine and mesencephalic reticular formation predominantly in its medial part (Fig. 2A). The c-Jun-positive neurons in the reticular formation varied in size and included very large $(>25 \mathrm{~mm}$ in diameter) neurons. Labeled neurons generally were more numerous in the medullary reticular formation than in the pontine and mesencephalic reticular formation. Other brainstem regions consistently showing c-Jun positive neurons included the deep cerebellar nuclei, the lateral vestibular nuclei, the red nucleus, the dorsal and most lateral part of the periaquaductal grey and the deep layers of the superior colliculus. No changes in c-Jun expression were observed in the cerebellar cortex, and in diencephalic and telencephalic brain regions of symptomatic SODl(G93A) mice. In pre-symptomatic SOD1(G93A) mice the distribution of c-Jun expression in the brainstem was identical as in nontransgenic littermates.

In the present study we have shown that c-Jun-immunoreactivity is strongly expressed in the brainstem and spinal cord of symptomatic SOD1(G93A) mice. c-Jun expression was not induced in pre-symptomatic SOD1(G93A) mice. This demonstrates that c-Jun induction is not a direct consequence of transgene expression, but is related specifically to the degenerative process caused by the mutated SOD1 gene. c-Jun immunolabeling in control mice was consistent with previous descriptions in rat [6], and did not occur in neurons known in rat to
A

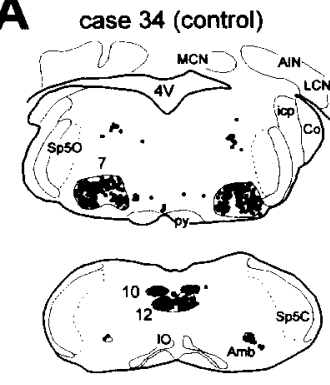

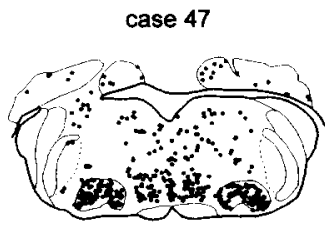

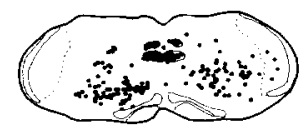

$1 \mathrm{~mm}$

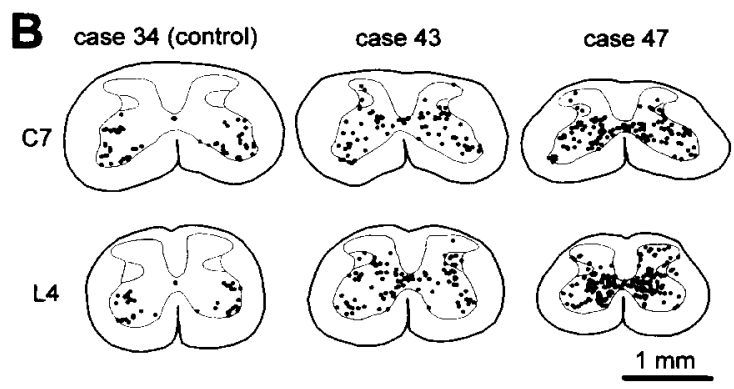

Fig. 2. Drawing of transverse $40 \mu \mathrm{m}$ sections of control (case 34) and transgenic SOD1(G93A) mice (cases 43 and 47) showing the distribution of c-Jun immunoreactive nuclei in the rostral and caudal medulla (A) and the spinal cord C7 and L4 segments (B). 7, Facial nucleus; 12, hypoglossal nucleus; $4 \mathrm{~V}$, fourth ventricle; Amb, ambiguus; AIN, anterior interposed nucleus; Co, cochlear nucleus; icp, inferior cerebellar peduncle; IO, inferior olive; LCN, lateral cerebellar nucleus; MCN, medial cerebellar nucleus; py, pyramidal tract; $\mathrm{Sp} 5 \mathrm{C}$ and Sp5O, spinal nucleus of the trigeminal nerve pars caudalis, and pars oralis, respectively. 
constitutively express other members of the jun-family, e.g. the hippocampal CA1 area, which contain junB-and junD-positive cells [6]. Hence, it is unlikely that c-Jun immunoreactivity in symptomatic $\operatorname{SOD}(\mathrm{G} 93 \mathrm{~A})$ mice is due to crossreactivity of the antibody with junB and junD.

The presence of numerous C-Jun-immunoreactive neurons in the intermediate zone of the spinal cord of symptomatic SOD1(G93A) mice is in line with data of Virgo and Belleroche [15] showing that the level of c-jun mRNA is increased in the lumbar spinal cord of patients with sporadic ALS, in particular in the intermediate zone. This suggests that motoneuron disease in SOD1(G93A) mice has mechanisms in common with sporadic ALS, and that intermediate zone neurons are involved in disease process of ALS.

Many neurons in the intermediate zone of the spinal cord project directly to motoneurons [11]. The brainstem areas displaying c-Jun-positive neurons in symptomatic SOD1(G93A) mice also contain neurons with direct projections to motoneurons in the spinal cord or the brainstem $[8,9]$. Inhibition of axonal transport and axon transection have shown to induce high C-Jun expression levels, suggesting that c-Jun expression is regulated by a targetderived signal $[7,12]$. Accordingly, in SODI(G93A) mice, c-Jun expression may have been retrogradely induced in 'premotoneurons' as a consequence of motoneuron degeneration.

c-Jun expression has been associated both with prevention and induction of neuronal death $[4,7,12]$. In a recent study employing a silver staining method specific for degenerating neurons, we have shown that argyrophilic neuronal degeneration occur in all areas, that according to the present study contain c-Jun positive neurons [10]. This suggests that the induction of c-Jun expression is connected with the degeneration of these neurons.

The authors are very grateful to Dr. Carol Linder (Jackson Lab.) for providing the PCR-protocol for hSOD1, and to Dr. C. Cozzari (Department of Cell Biology, CNR, Rome, Italy) for the kind gift of ChATantibody. Part of this study was funded by Het Prinses Beatrix Fonds (The Netherlands) and De Nederlandse Hersenstichting (The Netherlands).

(1) Cozzari, C., Howard, J. and Hartman, B., Analysis of epitopes on choline acetyltransferase (ChAT) using monoclonal antibodies, Soc. Neurosci. Abstr., 16 (1990) 91.6.
[2] Dal Canto, C. and Gurney, M.E., Development of central nervous system pathology in a murine transgenic model of human amyotrophic lateral sclerosis, Am. J. Pathol., 145 (1994) 1271-1280.

[3] Dragunow, M. and Preston, K., The role of inducible transcription factors in apoptotic nerve cell death, Brain Res. Brain Res. Rev., 21 (1995) 1-28.

[4] Estus, S., Zaks, W.J., Freeman, R.S., Gruda, M., Bravo, R. and Johnson, E. Jr., Altered gene expression in neurons during programmed cell death: identification of $c$-jun as necessary for neuronal apoptosis, J. Cell Biol,, 127 (1994) 1717-1727.

[5] Gurney, M.E., Pu, H., Chui, A.Y. et al., Motor neuron degeneration in mice that express a human $\mathrm{Cu}, \mathrm{Zn}$ superoxide dismutase mutation, Science, 264 (1994) 1772-1775.

[6] Herdegen, T., Kovary, K., Buhl, A., Bravo, R., Zimmermann, M. and Gass, P., Basal expression of the inducible transcription factors c-Jun, JunB, JunD, c-Fos, FosB, and Krox-24 in the adult rat brain, J. Comp. Neurol., 354 (1995) 39-56.

[7] Herdegen, T. and Zimmermann, M., Expression of c-Jun and JunD transcription factors represent specific changes in neuronal gene expression following axotomy, Prog. Brain Res., 103 (1994) $153-171$.

[8] Holstege, G. and Kuypers, H.G.J.M., The anatomy of brain stem pathways to the spinal cord in cat. A labeled amino acid tracing study. In H.G.J.M. Kuypers and G.F. Martin (Eds.), The Anatomy of Brain Stem Pathways to the Spinal Cord in Cat. A Labeled Amino Acid Tracing Study, Elsevier, Amsterdam, 1982, pp. $145-175$.

[9] Holstege, J.C. and Kuypers, H.G.J.M., Brainstem projections to spinal motoneurons: an update, Neuroscience, 23 (1987) 809-821.

[10] Jaarsma, D., Kennis, J., Troost, D., De Jong, J.M.B.V. and Holstege, J.C., Degeneration of spinal interneurons in addition to motoneurons in a trangenic mouse model for ALS, Soc. Neurosci. Abstr., 22 (1996) 94.5.

[11] Jankowska, E., Interneuronal relay in spinal pathways from proprioceptors, Prog. Neurobiol., 38 (1992) 335-378.

[12] Leah, J.D., Herdegen, T., Murashov, A., Dragunow, M. and Bravo, R., Expression of immediate early gene proteins following axotomy and inhibition of axonal transport in the rat central nervous system, Neuroscience, 57 (1993) 53-66.

[13] Ripps, M.E., Huntley, G.W., Hof, P.R., Morrison, J.H. and Gordon, J.W., Transgenic mice expressing an altered murine superoxide dismutase gene provide an animal model of amyotrophic lateral sclerosis, Proc. Natl. Acad. Sci. USA, 92 (1995) 689-693.

[14] Rosen, D.R., Siddique, T., Patterson, D. et al., Mutations in Cu/Zn superoxide dismutase gene are associated with familial amyotrophic lateral sclerosis, Nature, 362 (1993) 59-62.

[15] Virgo, L. and de Belleroche, J., Induction of the immediate early gene c-jun in human spinal cord in amyotrophic lateral sclerosis with concomitant loss of NMDA receptor NR-1 and glycine transporter mRNA, Brain Res., 676 (1995) 196-204.

[16] Wong, P.C., Pardo, C.O., Borchelt, D.R. et al., An adverse property of a familial ALS-linked SOD1 mutation causes motor neuron disease characterized by vacuolar degeneration of mitochondria, Neuron, 14 (1995) 1105-1116. 